\title{
MODIFICATION AND DEFENCE OF THE SCLERAL IMPLANT $*$
}

\author{
BY \\ W. HEDLEY SUMMERSKILL \\ Ophthalmic Surgeon, Portsmouth Eye and Ear Hospital, \\ and St Mary's Hospital, Portsmouth
}

SOME form of orbital implant is essential if the disfigurement caused by the loss of an eye is to be adequately disguised by a movable life-like prosthesis. A satisfactory implant will retain the contours and tone of the lids, provide a fully mobile foundation for the prosthesis, and preserve the conjunctival fornices.

The enthusiasm with which the technique of the integrated implant was adopted reflected a general dissatisfaction with the results being obtained by the older methods. But the long-term results of such implants are still unsatisfactory (Choyce, 1952; and others), since the majority become gradually immobilized or extruded by inflammatory fibrosis. It is to the completely buried implant that one must again turn to achieve any progress in this field.

The prototypes of the buried implant are those of Mules (1885), who described the introduction of a glass ball into the scleral cup provided by evisceration, and of Frost (1885a), who recommended the insertion of a sphere into Tenon's capsule after enucleation. Frost (1885b) and many other surgeons condemned Mules's procedure and, after a long controversy about the dangers of scleral implantation, this method was virtually abandoned aftér 1920.

An implant into Tenon's capsule can never provide a perfect foundation. Enucleation destroys the attachment of Tenon's capsule to the optic nerve and opens the central space within the muscle cone. The implant, therefore, lies insecurely in a tube leading to intra-orbital fat, a tissue highly sensitive to intra-orbital pressure changes. Examination of such implants shows that both atrophy and displacement of the fat are caused by the surgical trauma and later by the backward pressure of the sphere. The fat beneath the septum orbitale retracts, causing the characteristic unsightly depression beneath the brow, flattened fornices, and lax and sunken lids often in ectropion. An appearance of enophthalmos and a gradual loss of movement follow, as the inadequately supported ball is pulled towards the apex of the orbit. The surgery on the muscles also produces, immediately or later, some

\footnotetext{
- Received for publication April 4, 1953.
} 
limitation of movement. This sequence of events spoils the result of most Frost implants to some degree, and the resultant deformity is so characteristic in many cases that the presence of a prosthesis can be recognized at a glance (Figs 1, 2, and 3).
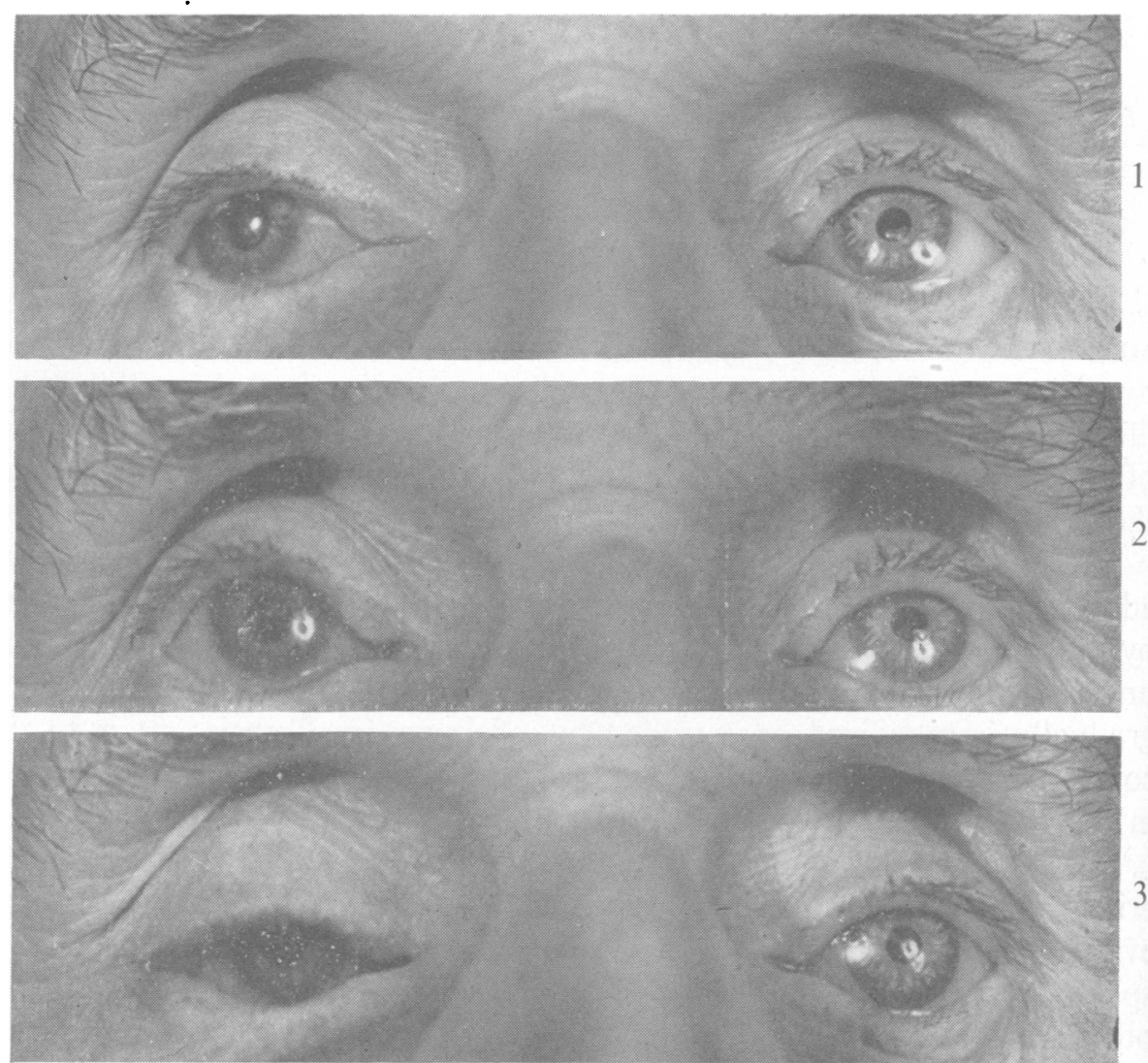

Figs 1, 2, and 3 .

Right-Summerskill-Mules's implant.

Left-Frost implant.

The surgery of Mules's implant, on the other hand, does not disturb the intra-orbital fat, the extrinsic muscles, or Tenon's capsule; therefore, when successful, it provides an almost perfect foundation for a life-like ocular prosthesis (Figs 4 and 5, opposite).

Unfortunately, the technique originally described by Mules involved a high proportion of failures and some danger. As a result of his war experiences, Valois (1918), among many others, condemned Mules's operation because of its frequent failures (extrusion of the ball), the prolonged and severe reaction which it provoked, and the danger of sympathetic ophthalmia. Its supporters felt they should be guided by the experience of the majority:

Our own experience of evisceration (including in that term Mules's operation) was considerable, and we never saw any case of sympathetic trouble, but we have abandoned 

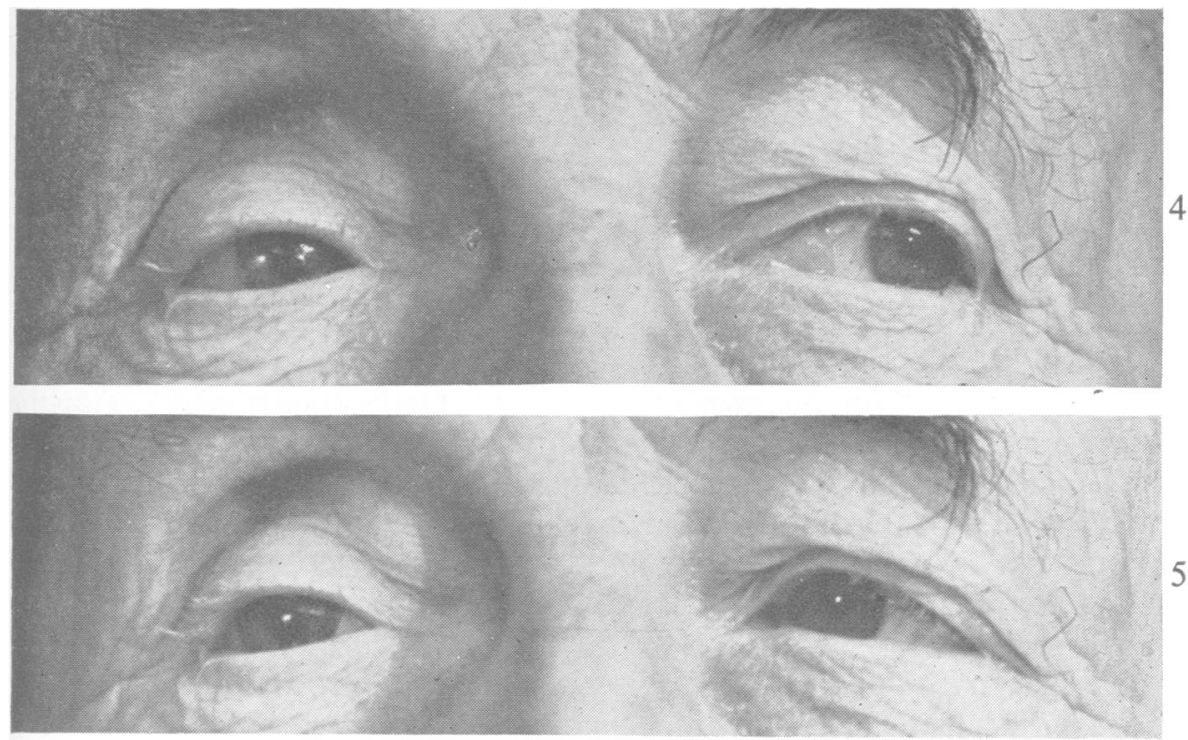

Figs 4 and 5.

Right-Summerskill-Mules's implant. Left-Normal eye.

Mules's operation because the total experience of the profession seemed to show that the risks were excessive (Grimsdale and Brewerton, 1937).

As a result this operation is now rarely used and modern text-books do not refer to it (Stallard, 1950; Philps, 1950; Wiener and Alvis, 1939). Spaeth (1944) described Mules's technique but considered that:

The postoperative course is never as uneventful, the reaction is more marked, the period of hospitalization is greatly increased, postoperative extrusion of the sphere (whatever the sphere may be) is much more common, and the final stump is actually smaller than that obtained by other procedures.

The author's experience with Mules's original technique confirmed many of Spaeth's criticisms, but he found that when successful its results fully justified the opinion of Swanzy and Werner (1907):

No proceeding is more satisfactory, at least in young persons, than this beautiful one of Mules. The prosthesis it gives is almost perfect.

The author, therefore, considered the merits of this operation deserved to be re-examined in the light of modern surgical practice and the validity of the objections to its use reassessed.

The literature shows that Mules's operation was discredited because:

(1) it was frequently followed by sympathetic ophthalmia,

(2) post-operative infections were common,

(3) a severe and painful reaction often caused expulsion of the implant,

(4) it did not produce a stump as mobile and satisfactory as that obtained by other procedures,

(5) the ball was liable to do serious damage to the orbital contents by bursting. 
(1) Sympathetic Ophthalmia.- $A$ priori there is little to justify an assumption that a properly conducted evisceration, with or without an implant, could initiate this disease. In the literature the issue is confused because Mules unfortunately advised the operation as a substitute for the enucleation of eyes threatened by sympathetic disease. He described the introduction of evisceration (1885) as:

Frohlich one accidental case in 1881 to extract a foreign body; Graefe in 1884 for the prevention of purulent meningitis; Mules in 1884 for the prevention of sympathetic ophthalmia ...

Since this was his claim, evisceration with scleral implant was used and judged as an operation "for the prevention of sympathetic ophthalmia", with the inevitable unfortunate results so often recorded. Sometimes Mules's operation was even used for established sympathetic ophthalmia, and at others it was provoked by incomplete removal of the uveal tissue (Valois, 1918). Moreover the diagnosis of sympathetic ophthalmitis was not always correct (Grimsdale and Brewerton, 1937), for these implants may cause a harmless sympathetic irritation (DukeElder, 1940).

There is, in fact, no convincing evidence in the literature that scleral implantation causes sympathetic disease if the operation is correctly performed and the cases are properly selected. Selection should not be difficult. Injured eyes requiring removal, if hopelessly damaged or badly infected, may be eviscerated within a few days of the injury and an immediate or delayed scleral implant inserted; eyes found to need removal later as a prophylactic measure against sympathetic ophthalmitis are unsuitable for scleral implantation.

(2) Postoperative InfeCtion.-The traumatized sclera, transformed into a closed sac containing an implant, is particularly vulnerable to invading pathogens. Mules (1885) reported that " of the first nine, the first six gave me some anxiety for they all suffered more or less" from infection and he was forced to remove three of the implants. There are many references in the literature to abscess formation, necrosis of the sclera, and orbital cellulitis with its attendant dangers especially among elderly people whose resistance was lowered, and Frost (1885b) reported that he found that " the sclera often slowly sloughs away". Infection should cause no anxiety under modern conditions; nevertheless, a scrupulous aseptic ritual should be observed for this operation. Infected eyes should be eviscerated and the implant inserted later when the socket is surgically clean.

(3) Postoperative Reaction with Extrusion of the Ball.-The observation that " a severe, dangerous and painful reaction was usual" (Frost, 1885b) after this operation was repeated by many surgeons during the next 50 years. It was probably the chief reason that the operation was abandoned.

Even under modern conditions of aseptic surgery, Spaeth (1944) was concerned by the marked reaction; it has also been the author's experience that Mules's original technique causes a very brisk reaction which is not due to infection. It consists of a severe conjunctival chemosis, oedema of the lids, and an increased tension in the scleral cavity. The orbital tissues become tense and tender accompanied by a severe neuralgia of the first division of the fifth nerve. The suture line stretches, the stitches threaten to cut out of the softened sclera, and often the ball is expelled. 
The cause and treatment of this reaction has been the subject of much discussion in the past.

(a) It was considered to be due to chemical irritation from the glass of the Mules's ball. Many substitutes were, therefore, tried, including fat (Barraquer, 1904), lead-free glass (Burch, 1939), gold (Fox, 1909), and other substances, but with no success. If chemical irritation was a factor it is now eliminated by using biologically inert material for the implant.

(b) Post-operative haemorrhage into the scleral cavity has been blamed, especially when the removal of the uveal tissue was incomplete. Haemostasis should be secured before the sclera is sutured over the implant.

(c) The poor healing qualities of the sclera were indicted and attempts were made to protect the suture line by sectioning the recti (Fox, 1909), retaining the cornea (Gifford, 1900), and suturing conjunctiva and sclera in one layer (Grimsdale and Brewerton, 1937). Such devices were unsuccessful as the failure to heal was a secondary phenomenon.

(d) The author was impressed in the cases he did by Mules's method by the clinical resemblance of this reaction to an acute glaucoma. The condition is a tissue oedema, probably due to an increased capillary permeability reflexly provoked by the surgical trauma involved in removing the uveal tract. Such an oedema is seen after other surgical insults to the uvea, and moreover it does not develop after a delayed scleral implant in which the uveal tract has previously been removed. On the assumption that the primary cause of this reaction was the rise of intra scleral pressure, the author tried controlling it by providing two drainage holes through the sclera. He found this simple modification was successful in reducing the reaction to negligible proportions.

The use of an implant perforated and guttered to equalize the pressure within the sclera provided with subconjunctival drainage makes the post-operative course as uneventful as a simple enucleation.

(4) InAdequate Movement of THE Ball.-In the past the excellent cosmetic results of this operation have frequently been praised. Few surgeons have questioned it, but Spaeth (1944) says:

The reason given for these operations is that motion of the stump is thereby increased and the cosmetic appearance of the patient improved. Practically, the author cannot concur in this . . . the final stump is actually smaller than that obtained by other procedures. The scleral shell cannot contain a sphere of a size equal to one implanted into Tenon's capsule.

It is not correct that a bigger orbital implant will of necessity transmit more movement than a smaller one. The movements of the larger Frost ball are restricted by its inadequate support, by surgery on the extrinsic muscles, and by its tendency to migrate backwards. The Mules implant on the other hand is firmly enclosed in a scleral envelope with normal muscular attachments and rotates in intra-orbital fat undisturbed by surgery. There is, therefore, little limitation of movement and the results are permanent. Moreover any lag due to the inertia of the prosthesis is more pronounced with a Frost implant for it requires the heavier " reform" type of eye to fill up dead space, whereas the scleral implant needs only a light "shell" eye. A comparison of the results in a patient with both types of implant is given in Figs 4 and 5 (p. 417). The movement of the right prosthesis over a scleral implant is immeasurably better than that of the left after a Frost operation.

(5) Serious Damage by the Explosion of the Mules Ball.-This was often reported in the past as occurring either spontaneously or as the result of trauma; 
a recent case was seen by Stewart (1952), when house surgeon to the late P. Hay of Sheffield. The use of the grooved implant of solid polythene eliminates any such danger.

\section{CoNCLUSIONS}

Scleral implantation in theory is capable of providing a perfect foundation for a life-like ocular prosthesis. Nevertheless the practice of Mules's procedure was generally abandoned because of the dangers and failures so frequently reported. A survey of the literature makes it apparent that the technique employed and not the scleral implant was responsible for these bad results. The author has done twenty scleral implants by the method to be described and has found the post-operative course completely uneventful. Two delayed implants, introduced some years after the evisceration, were not retained because at that time he was attempting to introduce into these crumpled scleral shells the larger implant $(12-20 \mathrm{~mm}$.) used for immediate implantation. No difficulty has since been experienced with a smaller implant (8-10 mm. diameter) for such cases.

\section{Selection of Cases}

The operation is contraindicated when:

(a) the whole eye is required for pathological examination,

(b) sympathetic ophthalmitis or an active cyclitis is established or threatened,

(c) malignant disease is suspected,

(d) severe lacerations or loss of tissue leave insufficient sclera to cover even a small implant of $8 \mathrm{~mm}$. diameter.

In the presence of infection, evisceration followed by a later implant is indicated. This procedure can also be followed if the general condition of the patient makes the combined operation inadvisable although the latter involves no more strain than a simple enucleation.

\section{SURGERY OF SCLERAL IMPLANTATION}

INSTRUMENTS.-Those used for Mules's operation (except his special introducer) and a range of guttered, acrylic globes of 8 and $10 \mathrm{~mm}$. diameter for delayed implantation and $12,13.5,15,16.5,18$, and $20 \mathrm{~mm}$. diameter for immediate implantation. They are sterilized by boiling in a metal box with a perforated lid.*

IMMEDIATE IMPLANTATION.-General anaesthesia is advisable. The conjunctiva is cut as close as possible to the limbus, and undermined some $6 \mathrm{~mm}$. posteriorly, and the cornea is removed as usually described for evisceration. With scissors, two meridional cuts are made backwards in the sclera for $5 \mathrm{~mm}$. at 5 o'clock and 11 o'clock; these simplify the inspection and cleaning of the scleral cavity and enable an implant of a satisfactory size to be inserted.

* The implants and sterilizing box have been constructed from the author's design by Messrs. Down Bros. and Mayer and Phelps Ltd., 92, Borough High Street, London, S.E.1, and Messrs. Theodore Hamblin Ltd., 15, Wigmore Street, London, W.1. 
The contents of the sclera are now removed and its wall cleaned. Near the termination of each of the meridional cuts the conjunctiva is further undermined and a drainage hole of about $3 \mathrm{~mm}$. diameter is excised from the sclera. Before introducing the implant it is convenient to insert the first suture. It is passed between 2 o'clock and 8 o'clock in the scleral margin so as to produce an oblique suture line in the direction of the meridional cuts. The suture is left loose, its loop drawn to one side, a few drops of sulphacetamide 30 per cent. are instilled, and the implant is inserted on the introducer. The largest ball that can be covered easily and loosely by the sclera without any tension should be used. The first suture is now tied and two others are inserted on each side; for large eyes three on each side of the central suture may be required to close the gap satisfactorily. The conjunctiva is now sutured along an oblique line to cross the scleral suture line. Penicillin sulphathiazole powder is insufflated into the conjunctival sac; a pad and strapping are applied.

The post-operative reaction is negligible and healing should occur without incident. A prosthesis can be fitted after 3 weeks.

Delayed ImPLANTATION.-After evisceration, the sclera becomes a crumpled, cicatrized, shrunken mass lying immediately beneath the conjunctiva. It is easily exposed, but its cavity is reformed only with difficulty, as the wall is indented by bands of scar tissue. No attempt should be made to force a large implant into the scleral shell, but no difficulty should be found in introducing a ball of $8-10 \mathrm{~mm}$. The results are not so satisfactory as immediate implantation, but much better than simple evisceration.

General anaesthesia is advisable. The operation is delayed until all infection has subsided. An oblique incision is made through the conjunctiva across the white scleral remnants which can be seen through this membrane. The scleral mass is defined by undermining the conjunctiva. An incision is made through the scar which marks the site of the original opening and the cavity reformed by introducing scissors and "spreading" them. Difficulty is met from ridges caused by bands of scar tissue outside the sclera. The subsequent procedure is as above, except that the positions of the scleral suture line and drainage holes are determined by the shape of the scleral remnant. The conjunctiva is drawn together along a line crossing the scleral union, sulphathiazole-penicillin powder is insufflated, and a pad and strapping are applied.

\section{SUMMARY}

(1) A scleral implant in theory provides the perfect foundation for a lifelike prosthesis.

(2) Mules's technique gave good results when successful, but was abandoned because of certain dangers inherent in his method and a high proportion of failures. 
(3) A study of the objections to its use contained in the literature shows that they are not valid under modern conditions.

(4) A proper selection of cases, the strict observance of aseptic procedure, the use of a deeply grooved implant of biologically inert material and the provision of subconjunctival drainage from the scleral cavity eliminates the dangers and failures associated with Mules's original procedure.

(5) Methods of immediate and delayed implantation are described.

The author's thanks are due to Mr. A. E. Barrett, S.H.M.O. of the Portsmouth Hospital Group, and to Mr. Frampton Jones, prosthesis fitter to the Portsmouth Eye Hospital, for their help with these cases.

\section{REFERENCES}

Barraquer y Roviralta, J. (1904). “ XIV C.R. Congrès international de Médecine, Madrid, 1903 ", vol. 10 , p. 423 .

BurCH, F. E. (1939). Trans. Amer. Ophthal. Soc., 37, 272.

CHOYCE, D. P. (1952). British Journal of Ophthalmology, 36, 123.

DUKE-ELDER, S. (1940). "Textbook of Ophthalmology", vol. 3, p. 2325. Kimpton, London. Fox, L. WeBSTER (1909). Ophthalmoscope, 7, 6.

Frost, W. A. (1885a). Middlemore Prize Essay. (1885b). Trans. Ophthal. Soc. U.K., 5, 197.

GifFoRD, H. (1900). Knapp's Arch. Ophthal., 29, 422.

Grimsdale, H., and BREWERTON, E. (1937). " A Textbook of Ophthalmic Operations ", 3rd ed., pp. 120, 135. Baillière, Tindall and Cox, London.

Mules, P. H. (1885). Trans. Ophthal. Soc. U.K., 5, 200.

PHILPS, S. (1950). “Ophthalmic Operations". Baillière, Tindall and Cox, London.

Spatri, E. B. (1944). "The Principles and Practice of Ophthalmic Surgery ", 3rd ed., pp. 129, 140. Kimpton, London.

Stallard, H. B. (1950). " Eye Surgery". Wright, Bristol.

Stewart, R. L. (1952). Personal communication.

SwANZY, H. R., and WerNer, L. (1907). "Diseases of the Eye", 9th ed., p. 257. Lewis, London.

ValoIs, G. (1918). “"Les Borgnes de la Guerre”. Masson, Paris.

WIENER, M., and Alvis, B. Y. (1939). "Surgery of the Eye". Saunders, Philadelphia and London. 